\title{
Intelligence and Religiosity among Dating Site Users
}

\author{
Emil O. W. Kirkegaard ${ }^{1, *(1)}$ and Jordan Lasker ${ }^{2}$ (i) \\ 1 Ulster Institute for Social Research, London NW26 9LQ, UK \\ 2 Independent Scholar, Atlanta, GA 30332, USA; lasker@tutanota.de \\ * Correspondence: emil@emilkirkegaard.dk
}

Received: 12 September 2019; Accepted: 18 December 2019; Published: 23 December 2019

\begin{abstract}
We sought to assess whether previous findings regarding the relationship between cognitive ability and religiosity could be replicated in a large dataset of online daters (maximum $n=67 \mathrm{k}$ ). We found that self-declared religious people had lower IQs than nonreligious people (atheists and agnostics). Furthermore, within most religious groups, a negative relationship between the strength of religious conviction and IQ was observed. This relationship was absent or reversed in nonreligious groups. A factor of religiousness based on five questions correlated at -0.38 with IQ after adjusting for reliability ( -0.30 before). The relationship between IQ and religiousness was not strongly confounded by plausible demographic covariates ( $\beta=-0.24$ in final model versus -0.30 without covariates).
\end{abstract}

Keywords: intelligence; religion; religious belief; atheism; agnosticism; Christianity; Catholicism; Hinduism; Judaism; Islam; OKCupid; cognitive ability

\section{Introduction}

There has been long-standing interest in the relationship between religious beliefs and the behaviors and traits of the people who hold them, including crime proneness and antisocial behavior [1], personality [2], health [3], happiness, resilience [4], and cognitive ability or intelligence [5-9]. With respect to cognitive ability, over sixty studies spanning more than eight decades have consistently found that the nonreligious and nonbelieving tended to be somewhat, perhaps 4-8 IQ points (on a regular mean 100, SD 15 scale), more intelligent than the religious $[10,11]$. This result has also been found when analyzing aggregate data at the country level of analysis $(r=-0.60$ between religiosity and cognitive ability) [10] and across the states of the USA $(r=-0.55)$ [12]. Similar patterns have been seen with related constructs such as science knowledge [13]. While some studies used binary measures of religiousness (e.g., "do you believe in God?" or "are you an atheist?"), some studies investigated the relationship between the intensity or seriousness of religious belief and cognitive ability, generally finding that more devout believers tended to display lower cognitive ability than more liberal believers, excluding nonbelievers [14]. Those findings primarily concerned the belief in Christianity, because they were mostly conducted on Western populations. For example, Nyborg [15] computed average IQs by religious denomination for whites in the National Longitudinal Survey of Youth 1979 dataset; these results have been reproduced in Table 1 . 
Table 1. Mean cognitive ability scores (IQ) for Christian denominations. From Nyborg [15].

\begin{tabular}{|c|c|c|}
\hline Denomination & IQ & SD \\
\hline Episcopal/Anglican & 113.43 & 11.68 \\
\hline Jewish & 112.43 & 13.14 \\
\hline Atheist & 111.08 & 12.78 \\
\hline Agnostic & 109.13 & 14.21 \\
\hline Methodist & 108.33 & 13.41 \\
\hline Presbyterian & 107.74 & 13.55 \\
\hline Lutheran & 107.51 & 12.01 \\
\hline Protestant & 107.42 & 13.38 \\
\hline Disciples of Christ & 106.90 & 12.99 \\
\hline Roman Catholic & 106.66 & 12.98 \\
\hline Other & 106.43 & 13.65 \\
\hline Mormon & 106.16 & 12.87 \\
\hline United Church of Christ & 106.14 & 12.47 \\
\hline Bible Church & 106.09 & 14.21 \\
\hline Islam & 104.87 & 9.94 \\
\hline Personal Philosophy & 103.98 & 14.54 \\
\hline Holiness & 103.56 & 12.88 \\
\hline Baptist & 102.13 & 13.78 \\
\hline Pentecostal & 101.89 & 13.05 \\
\hline Total & 106.09 & 13.57 \\
\hline
\end{tabular}

Nyborg also ranked the denominations according to his own judgments of religious fundamentalism and found that more liberal denominations displayed higher IQs. Nyborg's rankings of religions by their liberality were not objective, however, as at least one critic has pointed out [12]. The relationship between religiosity and cognitive ability deserves further investigation with reported measures of religious conviction included alongside the consideration of multiple religions instead of Christianity alone. We aimed to do just that.

\section{The Present Study}

The present study examined the relationships between religious orientation, intensity of belief, and cognitive ability in the large, diverse OKCupid dataset. We hypothesized that:

1. Atheists and agnostics would be more intelligent than believers, with the possible exception of believers in Judaism (Jews).

2. Within religions, more devout individuals would be less intelligent than less devout ones.

3. For nonreligious groups (atheists/agnostics), we expected the more devout to be more intelligent.

A confirmation of our first hypothesis would replicate the findings from a large literature (referenced above and below) that generally finds advantages in cognitive ability for both atheists and agnostics (see above) and Jews [16-18]. Our second hypothesis relates to a common question in the literature regarding how religious fundamentalism - which we indexed through stated belief strength-is related to cognitive ability. Most studies of this question have found that both within and between (some religions are rated as generally more fundamentalist than others) religions, fundamentalism is related to lower cognitive ability. Our third hypothesis was not a replication. We supposed that among non-believers, those with greater certainty in their disbelief would be more 
intelligent. The idea behind this hypothesis was that certainty in disbelief would signal convictions regarding the validity of beliefs that cannot be addressed-perhaps through some mediator like cognitive style or reliance on intuition that we could not assess-and that beliefs that cannot be addressed (i.e., the existence of a god or gods) are likely to be "pseudoprofound" [19]. Addressing this hypothesis more fully would require data that are unavailable in our dataset, so any results regarding this hypothesis can only be taken tentatively.

The analysis by Kirkegaard and Bjerrekær [20] plotted estimated cognitive ability by religious orientation and the relationship between strength of belief and cognitive ability irrespective of religious group. We extended their analysis by including estimates of the relationship between strength of belief and cognitive ability within each group and assessing the impacts of various demographic variables such as sexual orientation, age, race/ethnicity, and country of origin on "latent religiousness," a factor score based on answers to five questions discussed in greater depth below.

\section{Materials and Methods}

We used data from the OKCupid dataset, a large $(n \approx 70 \mathrm{k})$ public dataset of dating service users [20]. Users of the service filled out many questions the site used in order to match them with potential partners. There were thousands of questions concerning diverse topics, including many devoted to religion. The data used in the present study were collected from 2014 to 2015 before being released in anonymized form, and covered responses to roughly 2500 questions. The dataset primarily contained subjects from English-speaking (Anglophone) countries ( $85 \%)$, but also had a significant number from other Western European countries like Germany. The sample was almost entirely Western ( $95 \%)$. As such, our sample probably suffered from WEIRD sampling bias [21].

We searched the documentation of the dataset to find variables related to religion or belief in god. We found there were two variables relating to user religious self-representation in the profile (religion box) and five questions related to religious belief. We used a previously compiled collection of fourteen questions used to measure cognitive ability [20]. While the full set of questions included in this cognitive ability measure was small, it has been found to be related to variables with known relationships to cognitive ability, including crime/antisocial behavior [22] and political interest/participation [20]. Paraphrased, these items included

1. Which is bigger, the earth or the sun?

2. STALE is to STEAL as 89475 is to what?

3. What is next in this series? $1,4,10,19,31$,

4. If you turn a left-handed glove inside out, it fits on your left or right hand?

5. In the line "Wherefore art thou Romeo?" what does "wherefore" mean?

6. How many fortnights are in a year?

7. Half of all policemen are thieves and half of all policemen are murderers. Does it follow logically that all policemen are criminals?

8. Which is longer, a mile or a kilometer?

9. When birds stand on power lines and don't get hurt, it's most likely because of what?

10. Etymology is?

11. If some men are doctors and some doctors are tall, does it follow that some men are tall?

12. A little grade 10 science: what is the Ideal Gas Law?

13. If you flipped three pennies, what would be the odds that they all came out the same?

14. Which is the day before the day after yesterday?

In the future it may be useful to assess the relationship these items have to gold standard cognitive test results, but that option was unavailable to us. We scored the items using item response theory with the R mirt package [23]. We included only subjects who had answered at least five cognitive ability questions in order to avoid low quality data. Given the number and ease of the questions, the possible 
selectiveness of the sample (i.e., dating site users can expect to be different from the general population in various ways), and the ability to cheat on these questions, it is likely there was range restriction. The scores from this approach were very strongly correlated with those scored using all available data $(r=0.97)$. The scores were then standardized to have a mean of zero and an SD of one. We used this scale instead of the more common 100/15, because this sample was likely above average in IQ to an unknown degree and we did not want to mislead the reader by setting 100 equal to our sample mean. We used other demographic indicators (sex, sexual orientation, age, location, and race), which were also given by users in their profiles as covariates.

\section{Results}

\subsection{Religious Orientation and Certainty}

During the process of building a profile, each user was given the choice to select their religious orientation from a dropdown menu. If they did, they were given a follow-up question asking them to describe their level of seriousness about their chosen stance on a four-point Likert-like scale with the options of "laughing about it", "not too serious about it", "somewhat serious about it", or "very serious about it". Figure 1 depicts mean cognitive ability scores by religious orientation, coded as the combination of position and the seriousness/strength of the (non)belief/stance.

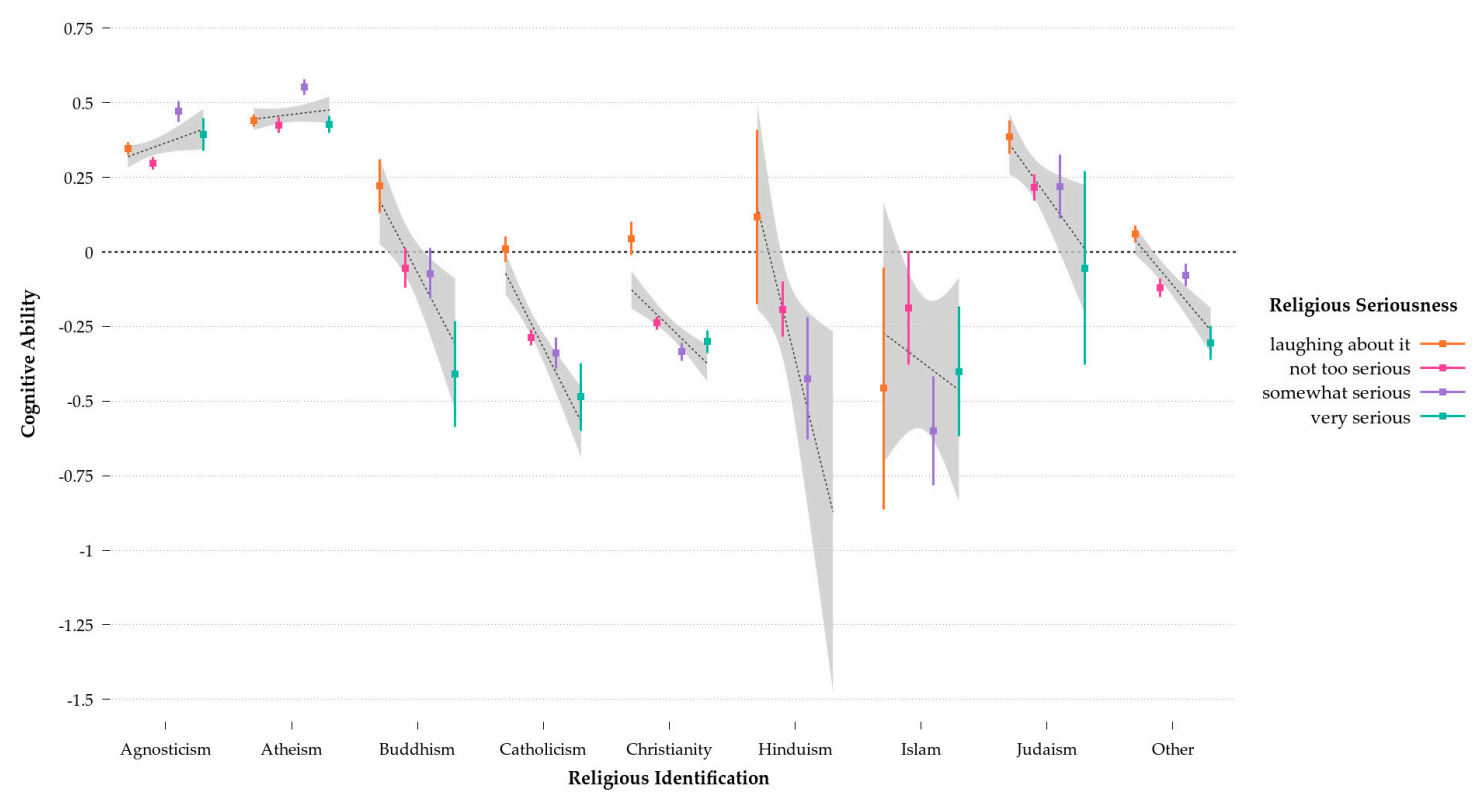

Figure 1. Mean cognitive ability by religious orientation and certainty. Error bars are $95 \%$ confidence intervals. Shaded regions are the $95 \%$ confidence intervals for the individual-level regression results. Groups without at least five cases are not shown.

In our data, the nonreligious had the highest mean cognitive ability but believers in Judaism were also notably above the sample mean. A similar pattern held inside most of the religious orientations: the least devout were the most intelligent. Some of the groups, particularly believers in Hinduism and Islam, were small $(n<200)$, and thus less likely to be representative, so their results should be taken tentatively. For the nonreligious stances, there was a weak pattern in the opposite direction for agnostics such that those who expressed more certainty in their beliefs were more intelligent than those who showed less certainty. This relationship was insignificant among atheists. It is possible that the insignificant result for atheists can be explained by an alternative interpretation; namely, that the correlation is there, but atheists are simply agnostics with greater certainty. The viability of this alternative explanation is something we were unable to assess. To evaluate these patterns further, 
we split the data by religious orientation and correlated cognitive ability with certainty. These results are given in Table 2.

Table 2. Religious orientation and polyserial correlation of cognitive ability with certainty. While Catholics are Christian, "Christianity" here refers to all non-Catholic Christians.

\begin{tabular}{cccccc}
\hline Religious Orientation & $N$ & Mean Cognitive Ability & $\begin{array}{c}\text { Correlation } \\
\text { with Certainty }\end{array}$ & $S E$ & $p$ \\
\hline Agnosticism & 5994 & 0.315 & 0.030 & 0.017 & 0.042 \\
\hline Atheism & 6991 & 0.441 & 0.011 & 0.016 & 0.240 \\
\hline Buddhism & 621 & -0.025 & -0.148 & 0.048 & 0.001 \\
\hline Catholicism & 2901 & -0.305 & -0.141 & 0.023 & $<0.001$ \\
\hline Christianity & 5762 & -0.308 & -0.085 & 0.017 & $<0.001$ \\
\hline Hinduism & 168 & -0.320 & -0.236 & 0.100 & 0.009 \\
\hline Islam & 149 & -0.541 & -0.062 & 0.126 & 0.310 \\
\hline Judaism & 906 & 0.247 & -0.103 & 0.041 & 0.007 \\
\hline Other & 4324 & -0.117 & -0.115 & 0.019 & $<0.001$ \\
\hline
\end{tabular}

For the large religious groups $(n>500)$, the results were all negative $(p \leq 0.01)$. For the nonreligious groups, they were closer to zero and only barely $p<0.05$ in the case of agnostics. Our results were only arguably consistent with Sickles et al.'s ([24], p.8) hypothesis that "controlling for levels of fundamentalist belief [is] likely to make any differences between theists and non-theists disappear."

As a robustness check, we carried out the analyses above in a subset of the data composed of only white Americans. The findings for Catholics, Christians, Buddhists, Jews, and others replicated in this subsample (all $p$ 's $<0.05$, and similar $r s$; values given in supplementary notebook). The lack of findings for the remaining groups could not be interpreted substantively due to very small sample sizes (e.g., $n$ white Hindus $=9$ ). All relationships investigated in the body of this paper were conducted for every racial group separately in the supplement.

\subsection{Demographic Covariates}

To see if the relationship between religiousness and intelligence was due to demographic confounders, we carried out a series of regressions incorporating demographic covariates. We utilized a variety of demographic labels that had not been extensively covered in prior literature, including sexual orientation and country of origin. Insofar as religions stigmatize nonheterosexual sexual orientations, it might be expected that these individuals would be particularly irreligious. Alternatively, as a response to religious or other stigmas, nonheterosexual individuals might gravitate towards spirituality as a means of managing that even if they do not gravitate towards organized religion per se. There are many possible hypotheses about and explanations for relationships between these variables and religiosity, but this is not the space for their elaboration, only their investigation. For this purpose, we created a religiousness factor based on five questions which were as follows:

1. How important is religion/god in your life? ["extremely", "somewhat", "not very", "not at all"]

2. Is your duty to religion/god the most important thing in your life? [yes/no]

3. Would you consider dating someone whose religion or spirituality is the primary focus in their life? [yes/no]

4. Do you believe in god? [yes/no]

5. Are you an atheist? [yes/no]

While the latter two questions may seem redundant, analysis revealed they were not, as approximately $24 \%$ of people who answered "no" to (4) answered "no" to (5), perhaps because 
they identified as agnostic or they interpreted atheism as something other than a lack of belief in $\operatorname{god}(\mathrm{s})$, or took it to imply other beliefs such as materialism. The items were subjected to a factor analysis, scored, and standardized. Individuals who answered fewer than three religion questions were excluded in order to avoid low-quality data. All items loaded as expected (i.e., positive loadings for 1-4, and negative for 5). After this, we fit regression models to predict each subject's level of religiousness (as the factor score). Results are given in Table 3.

Table 3. Regression models for predicting religiousness.

\begin{tabular}{|c|c|c|c|c|c|}
\hline Model & 1 & 2 & 3 & 4 & 5 \\
\hline Cognitive Ability & $-0.30(0.0057)$ & $-0.30(0.0058)$ & $-0.30(0.0058)$ & $-0.27(0.0060)$ & $-0.24(0.0058)$ \\
\hline Age & & (nonlinear) & (nonlinear) & (nonlinear) & (nonlinear) \\
\hline $\begin{array}{l}\text { Heterosexual } \\
\text { Female }\end{array}$ & & & (ref) & (ref) & (ref) \\
\hline Bisexual Female & & & $-0.29(0.0269)$ & $-0.29(0.0278)$ & $-0.26(0.0269)$ \\
\hline $\begin{array}{l}\text { Homosexual } \\
\text { Female }\end{array}$ & & & $-0.15(0.0516)$ & $-0.18(0.0538)$ & $-0.18(0.0520)$ \\
\hline Homosexual Male & & & $-0.11(0.0278)$ & $-0.15(0.0280)$ & $-0.19(0.0272)$ \\
\hline Bisexual Male & & & $-0.31(0.0407)$ & $-0.31(0.0423)$ & $-0.29(0.0409)$ \\
\hline Heterosexual Male & & & $-0.22(0.0139)$ & $-0.24(0.0142)$ & $-0.24(0.0138)$ \\
\hline White & & & & (ref) & (ref) \\
\hline Mixed & & & & $0.29(0.0195)$ & $0.25(0.0191)$ \\
\hline Asian & & & & $0.27(0.0293)$ & $0.18(0.0321)$ \\
\hline Hispanic & & & & $0.40(0.0297)$ & $0.35(0.0297)$ \\
\hline Black & & & & $0.71(0.0301)$ & $0.64(0.0294)$ \\
\hline Other & & & & $0.08(0.0360)$ & $0.15(0.0350)$ \\
\hline Indian & & & & $0.30(0.0603)$ & $0.31(0.0649)$ \\
\hline Middle Eastern & & & & $0.32(0.0948)$ & $0.31(0.0961)$ \\
\hline Native American & & & & $0.31(0.1288)$ & $0.17(0.1244)$ \\
\hline Pacific Islander & & & & $0.43(0.1369)$ & $0.46(0.1324)$ \\
\hline Country/State & & & & & (yes) \\
\hline$n$ & 37156 & 36436 & 36062 & 33158 & 33158 \\
\hline Adjusted $R^{2}$ & 0.088 & 0.105 & 0.114 & 0.143 & 0.205 \\
\hline
\end{tabular}

Standard errors are in parentheses. Nonlinear age was modeled using a restricted cubic spline. Country/state effects include dummies for US and Canadian states, and countries for everywhere else. Coefficients are standardized betas. "Ref" indicates that a category was a reference category for following variants of the same category; for instance, the reference category for the effect of sexual orientation was heterosexual females, so heterosexual males appear less religious than they do. The "(yes)" next to country/state indicates that those variables (of which there were many due to the large number of regions included in the dataset; see the supplement) were included.

Across all models, religiousness was negatively associated with cognitive ability. The inclusion of age (nonlinear), sex, sexual orientation, race, and residence (country/state) only modestly affected this finding ( $-20 \%, \beta$ changed from 0.30 to 0.24 ). Of note is that nonheterosexual sexual orientations, especially bisexuality, were negatively associated with religiousness in both sexes (except for homosexual males). All nonwhite races had higher levels of religiousness in this dataset. These associations were not meaningfully affected by the inclusion of location information. We also ran 
a model without the country/state variable and with an interaction term for whether the subject resided in an Anglophone country, but this term was insignificant $(\beta=-0.019, p=0.35)$. An interaction term for Western residence was also insignificant $(\beta=0.017, p=0.56)$, indicating that the relationship was unaffected by Western location. The full output from these models can be found in the supplementary materials notebook.

One particular limitation of the regression models above was that Jewish ethnicity was not separated from non-Jewish (gentile) white because the profiles did not offer an option to identify one's race/ethnicity as Jewish. However, another question was used to add clarity on this issue: "Are you Jewish?" [yes/no]. While this question was itself ambiguous regarding Jewish religion or Jewish ethnicity/race, it could be used to subset with since someone who is either should answer in the affirmative. The correlation between cognitive ability and religiousness among people who answered "yes" was -0.24 (95\% confidence interval: -0.29 to -0.19$)$, in line with the other results. The smaller value for this subset might have been due to range restriction, since only 1490 people answered this question.

Measurement error was likely to be a problem given our simple and limited measures. Estimated empirical reliabilities [25] for the two scales were 0.63 (cognitive ability) and 0.80 (religiousness). Correcting the observed correlation between cognitive ability and religiousness for measurement error using the Spearman-Brown prophecy formula resulted in a corrected estimate of -0.42 (from -0.30) [26]. This correction was necessary, because the factor score was derived from an exploratory and not a confirmatory factor analysis. Due to the exploratory nature of our factor analysis, we lacked more intricate model fit measures, and we cannot contest that our variables may have been more appropriately modeled with multiple dimensions; the fact that none of the variables had high uniqueness in the single factor model challenges this possibility, however. Alas, we had too few indicators to begin to address this issue. Thankfully, it is unlikely that our measures suffer from issues related to sample size or model complexity [27] because our sample size was large and a unidimensional model seemed appropriate.

\section{Discussion}

Previous research has documented a negative relationship between cognitive ability and religious belief $[10,11,14]$. Among the religious, the strength of religiosity has also been found to be negatively associated with cognitive ability [15]. Our results replicated both of these findings. On the other hand, the relationship between cognitive ability and the strength of religious convictions was absent or reversed in nonreligious groups like atheists and agnostics. Generally speaking, these results supported the general thrust of Nyborg's and many others' findings with regards to religiousness and cognitive ability $[10,15]$. The strength of the relationship in our dataset was stronger than in the meta-analysis we cited, which found an overall mean correlation of -0.16 [11], whereas ours was -0.30 . The meta-analysis did not utilize adjustments for measurement error, so the values may not be comparable. However, we suspected that the difference was mostly due to differences in the measures used and the sampled population. Many of the studies in the meta-analysis relied on cognitive ability measures such as SAT scores among college students, which are likelier to have had restricted range and which frequently feature erroneous score reporting. Consistent with this, the mean correlation found among adult noncollege samples was -0.23 , which is somewhat closer to our own. A recent large, multisample study that utilized measures of science knowledge and religiousness also found correlations around -0.30 , though these were reduced to about -0.20 when the questions did not include contested information (e.g., questions about global warming, and evolution) [13]. Item bias still has the potential to explain part or all of these relationships, as it did recently for the results of an actively open-minded thinking questionnaire [28]. It remains possible-though we were unable to test this-that these results may be explained by other mediators such as death salience, moral concern, conformism, attachment style, executive control, or analytical thinking style [29-32]. 


\section{Limitations}

There were a number of limitations to this study. First, data came from an online dating site where people answer questions in order to be better matched with potential partners. In this way, subjects had an incentive to answer truthfully insofar as this would enable them to be matched with similar people. However, the medium may also result in social desirability bias in responding; this response bias is probably more likely to be reflected in the answers to questions about one's religion than in answers to the cognitive ability-related questions unless cheating on these questions reflects social desirability bias. A previous study using this dataset for criminal and antisocial behavior did not indicate that social desirability bias was strong enough to remove expected criterion relationships [22]. Second, as an extension of the first limitation, the data were not particularly representative of the national populations they were drawn from but instead reflected mainly younger persons looking for love online. The regressions did not indicate notable biases from this sample selection. Third, the measure of intelligence was of somewhat questionable validity since it has not been tested against a well-validated test and is quite brief (14 items total and subjects did not usually respond to all 14). Future studies should test this battery against well-known cognitive ability tests in order to ascertain its psychometric qualities and potential demographic biases. Fourth, our sample is drawn mostly from Anglophone (about 85\%) and nearly entirely from Western (about 95\%) countries, so it is unclear to what degree these findings should generalize to populations not covered at all or which were only inadequately covered by our study. We suggest that future studies examine the relationship between cognitive ability and religiosity in countries with markedly different cultures than Western ones such as Brazil or China. Fifth, previous reviews on the topic highlighted the possible mediating role of education [11], but we were unable to test this mediation because our sample consisted mostly of people who had not yet finished formal education and, as a result, the education data available to us were not suitable for this analysis.

Supplementary Materials: Full statistical output and R code is available at http://rpubs.com/EmilOWK/intell_rel igion_OKCupid, data files are available following pointers in https://openpsych.net/paper/46.

Author Contributions: Conceptualization, E.O.W.K.; methodology, E.O.W.K.; formal analysis, E.O.W.K.; data curation, E.O.W.K.; writing-original draft preparation, E.O.W.K., J.L.; writing-review and editing, J.L.; visualization, J.L. All authors have read and agreed to the published version of the manuscript.

Funding: This research received no external funding.

Conflicts of Interest: The authors declare no conflicts of interest.

\section{References}

1. Evans, T.D.; Cullen, F.T.; Dunaway, R.G.; Burton, V.S. Religion and Crime Reexamined: The Impact of Religion, Secular Controls, and Social Ecology on Adult Criminality*. Criminology 1995, 33, 195-224. [CrossRef]

2. Saroglou, V. Religion and the five factors of personality: A meta-analytic review. Personal. Individ. Differ. 2002, 32, 15-25. [CrossRef]

3. Koenig, H.G. Religion, Spirituality, and Health: The Research and Clinical Implications. Available online: https://www.hindawi.com/journals/isrn/2012/278730/ (accessed on 20 August 2019).

4. Javanmard, G.H. Religious Beliefs and Resilience in Academic Students. Procedia-Soc. Behav. Sci. 2013, 84, 744-748. [CrossRef]

5. Souza, T.C.; Cribari-Neto, F. Intelligence and religious disbelief in the United States. Intelligence 2018, 68, 48-57. [CrossRef]

6. Cribari-Neto, F.; Souza, T.C. Religious belief and intelligence: Worldwide evidence. Intelligence 2013, 41, 482-489. [CrossRef]

7. Ritchie, S.J.; Gow, A.J.; Deary, I.J. Religiosity is negatively associated with later-life intelligence, but not with age-related cognitive decline. Intelligence 2014, 46, 9-17. [CrossRef] [PubMed]

8. Clark, R. Religiousness, Spirituality, and IQ: Are They Linked? Explor. An Undergrad. Res. J. 2004, 1, $35-46$.

9. Bertsch, S.; Pesta, B.J. The Wonderlic Personnel Test and elementary cognitive tasks as predictors of religious sectarianism, scriptural acceptance and religious questioning. Intelligence 2009, 37, 231-237. [CrossRef] 
10. Dutton, E. Religion and Intelligence: An Evolutionary Analysis; Ulster Institute for Social Research: London, UK, 2014; ISBN 978-0-9573913-5-2.

11. Zuckerman, M.; Silberman, J.; Hall, J.A. The Relation Between Intelligence and Religiosity: A Meta-Analysis and Some Proposed Explanations. Personal. Soc. Psychol. Rev. 2013, 17, 325-354. [CrossRef]

12. Dutton, E. Nyborg's 'The Intelligence-Religiosity Nexus' and the Benefits of Consilience. Open Differ. Psychol. 2014. [CrossRef]

13. McPhetres, J.; Zuckerman, M. Religiosity predicts negative attitudes towards science and lower levels of science literacy. PLoS ONE 2018, 13, e0207125. [CrossRef] [PubMed]

14. Lewis, G.J.; Ritchie, S.J.; Bates, T.C. The relationship between intelligence and multiple domains of religious belief: Evidence from a large adult US sample. Intelligence 2011, 39, 468-472. [CrossRef]

15. Nyborg, H. The intelligence-religiosity nexus: A representative study of white adolescent Americans. Intelligence 2009, 37, 81-93. [CrossRef]

16. Lynn, R. The intelligence of American Jews. Personal. Individ. Differ. 2004, 36, 201-206. [CrossRef]

17. Lynn, R. The Chosen People: A Study of Jewish Intelligence and Achievement, 1st ed.; Washington Summit Publishers: Whitefish, MT, USA, 2011; ISBN 978-1-59368-036-7.

18. Te Nijenhuis, J.; David, H.; Metzen, D.; Armstrong, E.L. Spearman's hypothesis tested on European Jews vs non-Jewish Whites and vs Oriental Jews: Two meta-analyses. Intelligence 2014, 44, 15-18. [CrossRef]

19. Pennycook, G.; Cheyne, J.A.; Barr, N.; Fugelsang, J.A.; Koehler, D.J. On the reception and detection of pseudo-profound bullshit. Judgm. Decis. Mak. 2015, 10, 15.

20. Kirkegaard, E.O.W.; Bjerrekær, J.D. The OKCupid dataset: A very large public dataset of dating site users. Open Differ. Psychol. 2016. [CrossRef]

21. Henrich, J.; Heine, S.J.; Norenzayan, A. The weirdest people in the world? Behav. Brain Sci. 2010, 33, 61-83. [CrossRef]

22. Kirkegaard, E.O.W. Self-reported criminal and anti-social behavior on a dating site: The importance of cognitive ability. Open Differ. Psychol. 2018, 1. [CrossRef]

23. Chalmers, R.P. mirt: A Multidimensional Item Response Theory Package for the R Environment. J. Stat. Softw. 2012, 48, 1-29. [CrossRef]

24. Sickles, J.V.; Huskey, A.; Schrantz, K. The Relationship between Intelligence and Religiosity: A Critical Review of the Literature. J. Sci. Psychol. 2015. Available online: https://www.researchgate.net/profile/Caleb_Lack/publ ication/283062772_The_relationship_between_intelligence_and_religiosity_A_critical_review_of_the_literat ure/links/5628672708aef25a243bf104/The-relationship-between-intelligence-and-religiosity-A-critical-revi ew-of-the-literature.pdf (accessed on 20 December 2019).

25. DeMars, C. Item Response Theory; Understanding Statistics; Oxford University Press: Oxford, NY, USA, 2010; ISBN 978-0-19-537703-3.

26. Hunter, J.E.; Schmidt, F.L. Methods of Meta-Analysis: Correcting Error and Bias in Research Findings, 3rd ed.; SAGE: Thousand Oaks, CA, USA, 2015; ISBN 978-1-4522-8689-1.

27. Devlieger, I.; Rosseel, Y. Factor Score Path Analysis: An Alternative for SEM? Methodology 2017, 13, 31-38. [CrossRef]

28. Stanovich, K.E.; Toplak, M.E. The need for intellectual diversity in psychological science: Our own studies of actively open-minded thinking as a case study. Cognition 2019, 187, 156-166. [CrossRef]

29. Jack, A.I.; Friedman, J.P.; Boyatzis, R.E.; Taylor, S.N. Why Do You Believe in God? Relationships between Religious Belief, Analytic Thinking, Mentalizing and Moral Concern. PLoS ONE 2016, 11, e0149989.

30. Vail, K.E.; Arndt, J.; Abdollahi, A. Exploring the Existential Function of Religion and Supernatural Agent Beliefs Among Christians, Muslims, Atheists, and Agnostics. Pers. Soc. Psychol. Bull. 2012, 38, 1288-1300. [CrossRef] [PubMed]

31. Zuckerman, M.; Li, C.; Lin, S.; Hall, J.A. The Negative Intelligence-Religiosity Relation: New and Confirming Evidence. Pers. Soc. Psychol. Bull. 2019, 146167219879122. [CrossRef]

32. Pennycook, G.; Cheyne, J.A.; Seli, P.; Koehler, D.J.; Fugelsang, J.A. Analytic cognitive style predicts religious and paranormal belief. Cognition 2012, 123, 335-346. [CrossRef]

(C) 2019 by the authors. Licensee MDPI, Basel, Switzerland. This article is an open access article distributed under the terms and conditions of the Creative Commons Attribution (CC BY) license (http://creativecommons.org/licenses/by/4.0/). 